\title{
Bile Salt Surfactants in Micellar Electrokinetic Capillary Chromatography: Application to Hydrophobic Molecule Separations
}

\author{
Roderic O. Cole and Michael J. Sepaniak* \\ Department of Chemisry, University of Tennessee, \\ Knoxville, TN 37996-1600, USA
}

\author{
Willie L. Hinze \\ Department of Chemistry,
} Laboratory for Analytical Micellar Chemistry, Wake Forest University, Winston-Salem, NC 27109, USA

\author{
Joesph Gorse and and Kimberly Oldiges \\ Department of Chemistry \\ Balwin-Wallace College \\ Bera, OH 44017, USA
}

* Author to whom correspondence should be addressed

\section{DISCLAIMER}

\footnotetext{
This report was prepared as an account of work sponsored by an agency of the United States Government. Neither the United States Government nor any agency thereof, nor any of their empioyces, makes any warranty, express or implied, or assumes any legal liability or responsibility for the accuracy, completeness, or usefulness of any information, apparatus, product, or process disclosed, or represents that its use would not infringe privately owned rights. Reference herein to any specific commercial product, process, or service by trade name, trademark, manufacturer, or otherwise does not necessarily constitute or imply its endorsement, recommendation, or favoring by the United States Government or any agency thereof. The views and opinions of authors expressed herein do not necessarily state or reflect those of the United States Government or any agency thereof.
} 


\section{SUMMARY}

Bile Salt surfactants are used in the micellar electrokinetic capillary chromatography (MECC) separation of various hydrophobic compounds. The use of methanol in the mobile phase allows the separation of previously intractable compounds including polyaromatic hydrocarbons. The effects of methanol on critical micelle concentration is investigated for sodium dodecyl sulfate (SDS) and the bile salt sodium cholate. It is determined that the unique structure of the bile salt micelle is much more tolerant to the addition of organic solvents than SDS, thereby increasing the scope of applications of MECC to include hydrophobic compounds.

\section{Introduction}

Micellar Electrokinetic Capillary Chromatography (MECC) is a form of Capillary Zone Electrophoresis (CZE) which offers unique selectivities as well as the ability to separate neutral compounds. CZE separates charged solutes based on their migration rate in an electric field [1]. In the case of neutral compounds, no separation is usually observed for this separation mode. MECC involves the addition of a ionic surfactant such as sodium dodecyl sulfate (SDS) to the mobile phase above the critical micelle concentration (CMC). The micelles are retarded in the electric field and move at a velocity slower than electroosmotic flow. In this situation, neutral solutes can partition between the micellar (pseudostationary) phase and the mobile phase, resulting in separation. Due to the fact that the micellar phase is moving toward the detector, an elution window is created that is bordered by a column void time $\left(t_{0}\right)$ and a micelle migration time $\left(t_{m}\right)$. As a result of this limited range, hydrophobic compounds (spending the bulk of the separation time associated with the micelle) tend to "stack up" (i.e. coelute) near $t_{m}$. Since resolution in MECC is optimal for $\mathrm{k}^{\prime}$ in the range of $1-5[2]$, depending on the 
breath of the elution window the technique is limited to compounds that are relatively hydrophilic.

In an effort to extend the utility of the technique to more hydrophobic species, organic solvents such as methanol have been added to the mobile phase $[3,4]$. Organic solvents affect the MECC separation process in two ways. First, the organic solvent slows electroosmotic flow by interacting with the capillary wall and thereby extends the micelle migration time and thus the elution window [3]. Extension of the elution window is concomitant with an increase in peak capacity. Second, the partition ratio is altered by decreasing the overall polarity of the mobile phase. Solutes which are insoluble in water distribute more equitably between micellar and mobile phases (i.e. $\mathrm{k}^{\prime}$ is reduced). Moreover, this approach provides an element of selectivity [4]. These effects have allowed the development of step and continous gradient elution techniques for MECC $[5,6]$.

Relatively high concentrations of organic solvents degrade separation performance. At levels exceeding approximately $15 \%$ $(v / v)$, efficiency begins to show significant reduction and analysis time becomes prohibitive [6]. Band broadening in this situation is attributed to micelle polydispersity [10]. Analysis time is dependant on the amount and type of organic solvent employed. Methanol and 2-propanol greatly extend the elution range, presumably due to strong wall interaction and thus significantly alter eiectroosmotic flow. In some cases, the flow can be reduced to a point where the electrophoretic mobility of the micelle exceeds electroosmotic flow 
and migrates toward the positive electrode, away from the detector [7]. Other solvents such as acetonitrile and dioxane reduce solute capacity without dramatically reducing flow, presumably due to less wall interaction.

When SDS is used as the pseudostationary phase, separations of extremely hydrophobic molecules such as polyaromatic hydrocarbons (PAH) are often unsuccessful. Hydrophobic species usually coelute at $t_{m}$ despite the addition of large $(\geq 20 \%)$ amounts of organic solvent to the mobile phase. Additives such as cyclodextrins have been used with SDS to separate compounds such as PAH, chlorinated biphenyls and dioxins [27]. While successful, this approach is limited to solutes which can fit into the cyclodextrin cavity.

As an alternative surfactant system, the bile salts have found application in MECC. Bile salts exhibit several useful chromatographic properties such as the ability to recognize specific enantiomeric conformations $[8,9,10]$ and increased micelle polarity [10,11]. Based on a hydroxyl-substituted steroid backbone, bile salts are important biological surfactants which possess both hydrophobic and hydrophilic "faces". Figure 1 shows the structures of the bile salts used in this work. While the physical properties of bile salts have been extensively studied $[12,13]$, there has been some controversy over the structure of their micelles. In 1968, Small introduced a model in which the hydrophobic faces of the monomer units are proximal and the protruding hydroxyl groups face the bulk solution [14]. This model, based on logical consideration of spacefilling molecular models and interfacial behavior of the monomer 
units, has recently been expanded in light of more sophisticated experimentation. Recent studies $[15,16,17]$ suggest that the aggregates in question form helical micelles with the hydrophobic portions of the monomer facing the aqueous solution while the hydrophilic portions turn inward. Thus, in some respects, the bile salt micelle can be envisioned as an "inverted micelle". Studies with fluorescent and spin-label probe compounds lend further support to this argument [21,22].

The fact that the bile salt monomer is more polar than SDS leads to a general reduction of $k^{\prime}$ in $\operatorname{MECC}[8,10]$. This is particularly advantageous in dealing with hydrophobic compounds, as separations which prove difficult with conventional SDS systems are more easily attained with bile salts. In addition, the unique inverted bile salt micelle appears to tolerate high concentrations of solvents such as methanol without drastic loss of efficiency or dramatic increase in analysis time. These desirable characteristics allow separations of compounds never before performed with MECC. This paper presents several separations of hydrophobic compounds using bile salt mobile phases with high organic modifier content. Investigations of the effects of methanol on the critical micelle concentration (CMC) for both SDS and sodium cholate, a trihydroxy bile salt, are also reported. Reasons for the tolerance of the bile salt micelles to organic solvent are discussed. 
Experimental Section

1. Apparatus

Both absorbance and laser-based fluorescence were used in this study. Fluorescence excitation was provided by a Liconics model $423 \mathrm{OMB}$ helium-cadimum laser(Sunnyvale, CA) operated at $325 \mathrm{~nm}$. Collection of fluorescence emission was as described elsewhere [10]. Parameters süch as detection wavelengths, column length, mobile phase composition, and applied voltage are given in the text. Absorbance spectra were measured on a Perkin-Elmer model lambda 3B dual-beam spectrometer. The sample cuvette was maintained at $30{ }^{\circ} \mathrm{C}$ with a Perkin-Elmer model 0050405 temperature controller bath.

2. Chemicals

Sodium sholate $(\mathrm{NaC})$, sodium deoxycholate $(\mathrm{NaDC})$ and SDS were obtained from Sigma (St. Louis, MO.). Rhodimine 6G, amines, and 7-chloro4-nitrobenzo-2,1,3-oxadiazole (NBD-Cl) were purchased from Eastman Kodak (Kingsport, TN.). NBD-Cl derivatization of amines has been described previously [20]. All solvents were of HPLC grade and were purchased from Baxter Chemical Co. PAH and aflatoxins were obtained from Aldrich Chemical Company (Milwaukee, WI). Benzo(a)pyrene tetrol was obtained from Midwest Research Institute (Kansas City MO). Structures for compunds studied are depicted in Figure 2. 
3. Procedures

Injections were made by a common syphoning procedure [5]. Column pretreatment and equilibration was as described earlier [10]. Due to the very limited water solubility of some of the compounds studied, the samples were dissolved in methlene chloride and extracted into mobile phase or further dissolved in methanol followed by dilution with an approximately $50 \%$ micellar solution. Injections from pure organic solvent were avoided to prevent problems with electric field distortions and loss of current.

CMCs were estimated via dye solubilization as described by Small [12]. This procedure consists of measuring the wavelength of maximum absorbance for a dye (Rhodamine 6G) under varying concentrations of bile salt and methanol. The wavelength of maximum absorbance $(\lambda \max )$ is measured for each concentration and plotted against the logarithm of the surfactant concentration. All $\lambda$ max values are the average of three measurements.

\section{Results and Discussion}

In first evaluating the bile salts for hydrophobic separations, a well-characterized test mixture of derivatized n-alkyl amines were employed. To better estimate $t_{m}$ and separation performance, a mixture of NBD derivatives was made: methyl, propyl, pentyl, octyl $\left(\mathrm{C}_{8}\right)$, decyl $\left(\mathrm{C}_{10}\right)$, dodecyl $\left(\mathrm{C}_{12}\right)$ and tetradecyl $\left(\mathrm{C}_{14}\right)$ amine were included. The late eluting derivatives $\left(\mathrm{C}_{8}-\mathrm{C}_{14}\right)$ serve to gauge hydrophobic compound separation performance as well as mark the micelle migration time. Figure 3 shows the separation of these 
compounds with $\mathrm{NaC}$ and SDS. Retention time increases linearly with increasing carbon chain length, so elution order is the same for both systems. Note that the late-eluting solutes are partially resolved with the $\mathrm{NaC}$. As mentioned above, the more polar micelle allows for $k^{\prime}$ values more near the optimum range.

An enviromentally significant example of the capabilities of MECC using bile salts is shown in Figure 4; the separation of the aflatoxins $\mathrm{G}_{1}, \mathrm{G}_{2}$, and $\mathrm{B}_{2}$ with a sodium deoxycholate $(\mathrm{NaDC})$ pseudostationary phase. Aflatoxins are extremely toxic compounds found in spoiled foodstuffs [29]. Baseline separation of these compounds has been reported with SDS, but only after addition of organic solvent [23]. In this case, baseline resolution is obtained for all three compounds without the use of organic modifiers, thus saving analysis time. Coupled with the sensitivity of laser-based fluorescence, bile salt MECC offers a rapid assay for these toxins.

Further improvements in resolution are attained when methanol ss added to the mobile phase. Figure 5 shows the separation the aforementioned NBD-amines using a mobile phase containing $20 \%$ methanol. With the $\mathrm{NaC}$ system, all of the more hydrophobic $\left(\mathrm{C}_{8}-\mathrm{C}_{14}\right)$ amine derivatives are fully resolved, with reasonable efficiency. In contrast, the SDS system allows resolution of only the $C_{8}$ from the $C_{10}-C_{14}$ amine derivatives which coelute at $t_{m}$. In addition, analysis time for the SDS is roughly three times that for the $\mathrm{NaC}$. Efficiency is much poorer with the SDS system, presumably due to micelle polydispersity. Micelle polydispersity arises when the micelles have a range of aggregation numbers, leading to the formation of micelles with a possible range of electrophoritic 
mobilities. Solutes that associate with the micelles can experience a similar range of velocities and thereby become dispersed. This mechanism is thought to be a significant source of band dispersion in MECC $[6,24,25]$. The micelle polydispersity problem is most acute at or near the CMC [6]. Addition of organic solvent can lead to the onset of this problem at surfactant concentrations where this is us rally not the case. When methanol is added to the mobile phase, the overall solution polarity is decreased. This presumably reduces the affinity of the hydrophobic tails of the SDS monomers for one another, causing an increase in CMC [30]. Conversely, the helical structure of the bile salt micelle, since it resembles a reversed or inverted micelle, might be expected to be less vulnerable to disassociation by a reduction in the polarity of the bulk solution. The methanol-modified mobile phase might be favored by the hydrophobic face of the monomer, possibly stabilizing the micelle relative to SDS.

The impact of methanol content on micelle formation was studied by estimating the CMC for both SDS and $\mathrm{NaC}$ under MECC mobile phase conditions. Dye solublization was the method used in this study [12]. The wavelength of maximum absorbance was measured between 520 and $580 \mathrm{~nm}$ for Rhodamine $6 \mathrm{G}$ at several different $\mathrm{NaC}$ concentrations. Plots of $\lambda \max v s . \log (\mathrm{NaC})$ were constructed over a range of methanol concentrations. Figure 6 shows a sample plot. The first shift in $\lambda \max$ is taken as an estimate of the CMC. As the concentration of $\mathrm{NaC}$ is increased past the $\mathrm{CMC}$, $\lambda$ max continues to shift until a plateau is reached. The shape of the plot is assumed to be the result of varying degrees of dye 
association with the micelle. As more micelles are formed, the dye interacts with increasing strength until a point is reached where the dye is completely micelle solublized, causing the wavelength shift to reach a maximum. The actual $\mathrm{CMC}$ could be taken as this plateau, the first shift, or the midpoint. We have arbitrarily chosen the first break point after the work of Small [12]. It should therefore be emphasized that the CMC values presented here are arbitrary estimates of the true CMC. The dependance of the CMC for SDS and $\mathrm{NaC}$ are shown in Figure 7. The CMC for SDS begins to rise at methanol levels above approximately $10 \%$, while $\mathrm{NaC}$ stays nearly constant until $30 \%$ methanol. Chromatographic efficiency for SDS reflects these trends [6]. As mobile phase methanol content increases, the efficiency with the SDS system shows a steady decrease. The same peak in the $\mathrm{NaC}$ system shows the same or even increased efficiency. Thus, the ability of $\mathrm{NaC}$ to tolerate the presence of organic solvent without significant loss of efficiency enhances the capabilities of MECC with regard to the separation of hydrophobic compounds.

One of the more challenging separation problems for MECC is that of polyaromatic hydrocarbons. To date, there are only two reports of PAH separations with electrophoretic techniques. The earliest approach to hydrophobic neutrals was a CZE separation based on solvophobic interactions leading to charged complexes. Ionic PAH complexes were separated by the usual CZE mechanism [26]. A more recent approach involving micellar solutions and cyclodextrins has also been applied to the separation of certain relatively small molecules [27]. Bile salt MECC to date offers relatively efficient 
separations of PAH as large as pyrene and benzo(a)pyrene (B(a)P), and more general applicability than other electrokinetic-based approaches. Figure 8 is the separation of anthracene, pyrene, and benzo(a)pyrene (B(a)P) with a $\mathrm{NaC}$ system. PAH larger than $\mathrm{B}(\mathrm{a}) \mathrm{P}$ can also be addressed by increasing the amount of organic modifier in the mobile phase. Baseline resolution is achieved at only $10 \%$ methanol, well in the efficient working range for $\mathrm{NaC}$. At $20 \%$ methanol, the resolution is further increased without drastic loss of efficiency, suggesting that $\mathrm{PAH}$ larger than $\mathrm{B}(\mathrm{a}) \mathrm{P}$ might be separated.

Substituted PAH such as hydroxy derivatives may also be separated with these systems. While more polar than unsubstituted PAH, these compounds are difficult to address with SDS pseudostationary phases. Hydroxy-substituted PAH play a critical part in determining the carcinogenity of $\mathrm{PAH}$, and metabolic pathways almost invariably terminate in hydroxy derivatives [28]. Figure 9 shows the separation of $\mathrm{B}(\mathrm{a}) \mathrm{P}$ from benzo(a)pyrene tetrol, one of the final forms in the metabolic pathway. This separation suggests that MECC could find application in monitoring ingestion and metabolic kinetics of PAH in biological systems.

Bile salt surfactants clearly exhibit practical advantages over conventional n-alkyl surfactants. Selectivity and applicability of MECC is expanded by their use. Unique selectivity is achieved by the highly ordered nature of the micelles; chiral separations are possible. In addition, the polar interior allows increased resolution for hydrophobic compounds, extending the utility of the technique to previously intractable separation problems. The inverted structure of the aggregates appears to permit relatively undisturbed micelle 


\section{1}

formation in the presence of organic modifiers, thereby allowing greater peak capacity. The data presented herein also offers indirect support for the helical structure model of the bile salt micelle. It is evident that these surfactants will find application in many separation problems.

ACKNOWLEDGEMENT

This work was sponsored by The Division of Chemical Sciences, Office of Basic Energy Sciences, United States Department of Energy, under grant DE-FG05-86ER13613 with the University of Tennessee. 


\section{REFERENCES}

1. Jorgenson, J. W., Lukacs, K. D., Anal. Chem. 53, (1981) 1298 1302.

2. Terabe, S., Otsuka, K., Ichikawa, K., Tsuchiya, A., Ando, T., Anal. Chem. 56, (1984) 111-113.

3. Balchunas, A. T., Sepaniak, M. J., Anal. Chem. 59, (1987) 14661470 .

4. Gorse, J., Balchunas, A. T., Swaile, D. F., Sepaniak, M. J., J. High Res. Chromatogr. and Chromatugr. Comm. 11, (1988) $\$ 54$.

5. Sepaniak, Mí. J., Swaile, D. F., Powell, A. C., J. Chromatogr. 480, (1989) 185-196.

6. Balchunas, A. T., Sepaniak, M. J., Anal. Chem. 60, (1988) 617621.

7. Jorgenson, J., Bushey, M., J. Microcol. Sep. 1, (1989) 125-130.

8. Terabe, S., Shibata, M., Miyashita, Y., J. Chromatogr. 480, (1989) 403-411.

9. Nishi, H., Fukuyama, T., Matsuo, M., Terabe, S., J. Chrom. 515, (1990) 233-243.

10. Cole, R. O., Sepaniak, M. J., Hinze, W. L., J. High Res. Chrom. 13, (1990) 579-582.

11. Nishi, H., Fukuyama, T., Matsuo, M., Terabe, S., J. Chromatogr. 498, (1990) 313-323.

12. Small, D. M., Carey, M. G., J. Colloid Interface Sci. 31, (1969) 382-395. 
13. Small, D. M., in P. P. Nair, D. Kritchevsky, Eds. The Bile Acids, Plenum Press, New York, 1971, pp. 249-356.

14. Small, D. M., Advan. Chem. Ser. (1968) 31.

15. Conte, G., Di Blasi, R., Gigilo, E., Parretta, A., Pavel, N. V., J. Phys. Chem. 88, (1984) 5720.5724.

16. Esposito, G., Giglio, E., Pavel, N. V., Zanobi, A., J. Phys. Chem. 91, (1987) $356 \cdot 362$.

17. Campanelli, A. R., De Sanctis, C., Chiessi, E., D'Alagni, M., Giglio, E., Scaramuzza, L., J. Phys. Chem. 93, (1989) 1536-1542.

18. Terabe, S., Nishi, H., Fukuyama, T., Matsıo, M., J. Microcol. Sep. 1, (1989) $234-242$.

19. Hinze, W. L., in W. L. Hinze, D. W. Armstrong, Eds. Ordered Media in Chemical Separations, American Chemical Society, Washington D. C., 1987, pp. 2-82.

20. Murray, G. M., Sepaniak, M. J., J. Liq. Chromatogr. 6, (1983) 931-939.

21. Kawamura, H., Manabe, M., Narikiyo, T., Igimi, H., Murata, Y., Sugihara, G., Tanaka, M., J. Solution Chem. 16, (1987) 433-441.

22. Fisher, L., Oakenfall, D., Aust. J. Chem. 32, (1979) 31-39.

23. Balchunas, A. T., Swaile, D. F., Powell, A. C., Sepaniak, M. J., Sep. Sci. Technol. 23, (1988) 1891-1904.

24. Sepaniak, M. J., Cole, R. O., Anal. Chem. 59, (1987) 472-476.

25. Terabe, S., Otsuka, K., Ando, T., Anal. Chem. 61, (1989) 251 260 .

26. Jorgenson, J., Walbroehl, Y., Anal. Chem. 58, (1986) 479-481.

27. Terabe, S., et al., J. Chrom. 516, (1990) 23-31. 
28. Becher, G., Bjørseth, A., in A. Bjørseth, T. Ramdahl, Eds.

Handbook of Polycyclic Aromatic Hydrocarbons Marcel Dekker, Inc., New York, 1985, pp. 237-2:2.

29. Zare, R. D., Diebold G. J., Science, 196 (1977) 1439-1441.

30. Magid, L., in K. L. Mittal, Ed. Solution Chemistry of Surfactants, , Plenum Press, New York, 1979, pp. 427-453. 


\section{FIGURE CAPTIONS}

1. Bile salt structures.

2. Structures of compounds investigated in this work.

3. Separation of NBD derivatized amines in (A) $\mathrm{NaC}$ and (B) SDS. Mobile Phase: $0.05 \mathrm{M}$ surfactant, $0.01 \mathrm{M} \mathrm{Na} 2 \mathrm{HPO}_{4}, 0.006 \mathrm{M} \mathrm{Na} 2 \mathrm{~B}_{4} \mathrm{O}_{7}$ Applied Voltage $15 \mathrm{kV}$, Column length: $50 \mathrm{~cm}, 45 \mathrm{~cm}$ to window. Detection: Argon ion laser fluorescence, $\lambda_{c x} 488 \mathrm{~nm}, \lambda_{\mathrm{em}} 540 \mathrm{~nm}$.

4. Separation of Alfatoxins: (1) G2, (2) B2, (3) G1 Mobile Phase: $0.05 \mathrm{M} \mathrm{NaDC}, 0.01 \mathrm{M} \mathrm{Na}_{2} \mathrm{HPO}_{4}, 0.006 \mathrm{M} \mathrm{Na}_{2} \mathrm{~B}_{4} \mathrm{O}_{7}$ Applied Voltage $16 \mathrm{kv}$, Column lengih $53 \mathrm{~cm}, 50 \mathrm{~cm}$ to window. Detection: HeCd laser fluoresence, $\lambda_{\mathrm{ex}} 325 \mathrm{~nm}, \lambda_{\mathrm{em}} 450 \mathrm{~nm}$.

5. Separation of NBD derivatized amines. Conditions identical with Figure 1 except mobile phases contain 20\% Methanol.

6. Sample plot of wavelength of maximum absorbance $v s . \mathrm{NaC}$ concentration. $\mathrm{CMC}$ is taken as first change in $\lambda \max$.

7. Critical micelle concentration dependance on mobile phase methanol content for SDS and $\mathrm{NaC}$. Mobile phases contain 0.01M Na $2 \mathrm{HPO}_{4}$, $0.006 \mathrm{M} \mathrm{Na}_{2} \mathrm{~B}_{4} \mathrm{O}_{7}$.

8. Separation of Polyaromatic hydrocarbons:

(1) Anthracene, (2) Pyrene, (3) Benzo(a)Pyrene.

Mobile phase: $0.05 \mathrm{M} \mathrm{NaC}, 0.01 \mathrm{M} \mathrm{Na}_{2} \mathrm{HPO}_{4}, 0.006 \mathrm{M} \mathrm{Na}_{2} \mathrm{~B}_{4} \mathrm{O}_{7}$

with (A) $10 \%$ Methanol and (B) $20 \%$ methanol.

Applied voltage $20 \mathrm{kv}$. Column length $53 \mathrm{~cm}$.

Detection: HeCd laser fluorescence, $\lambda_{\mathrm{cx}} 325 \mathrm{~nm}, \lambda_{\mathrm{em}} 400 \mathrm{~nm}$.

9. Separation of (1) Benzo(a)Pyrene tetrol and (2) Benzo(a)Pyrene Mobile phase: $0.05 \mathrm{M} \mathrm{NaC}, 0.01 \mathrm{M} \mathrm{Na}_{2} \mathrm{HPO}_{4}, 0.006 \mathrm{M} \mathrm{Na}_{2} \mathrm{~B}_{4} \mathrm{O}_{7}$ Applied voltage $16 \mathrm{kv}$, other conditions same as Figure 7. 


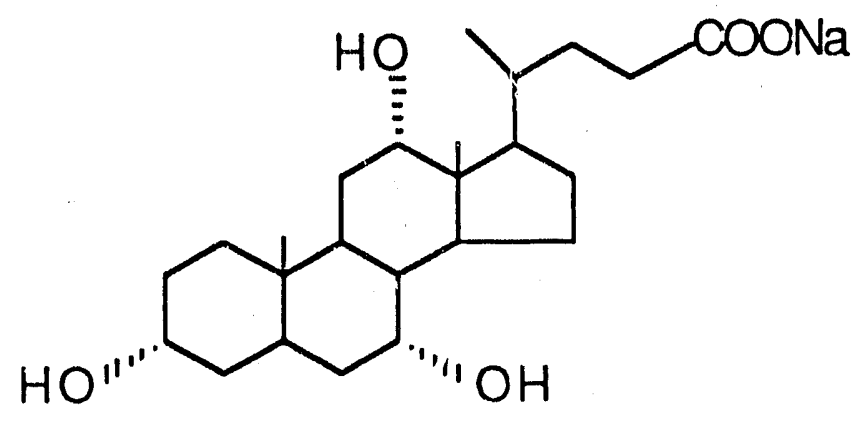

\section{SODIUM CHOLATE}

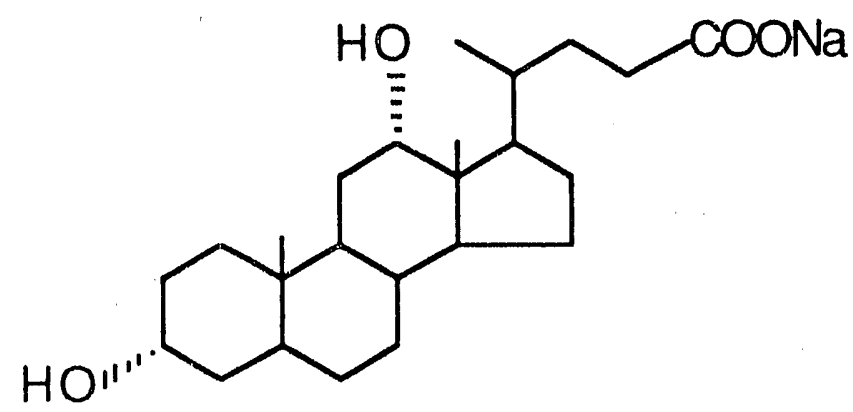

\section{SODIUM DEOXYCHOLATE}




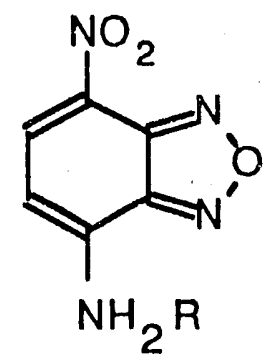

NBD-Amines $(R=n$-alkyl chain $)$

obo<smiles>[101InH]</smiles>

Pyrene

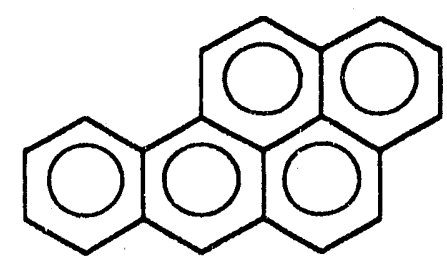

\section{Anthracene}

Benzo[a]Pyrene
Aflatoxin $\mathrm{G} 1$<smiles>COc1cc2c(c3oc(=O)c4c(c13)CCOC4=O)C1CCOC1O2</smiles>

Aflaioxin G2<smiles>COc1cc2c(c3oc(=O)c4c(c13)CCOC4=O)C1C=COC1O2</smiles><smiles>COc1cc2c(c3oc(=O)c4c(c13)CCCC4=O)C1CCOC1O2</smiles>

Aflatoxin B2 

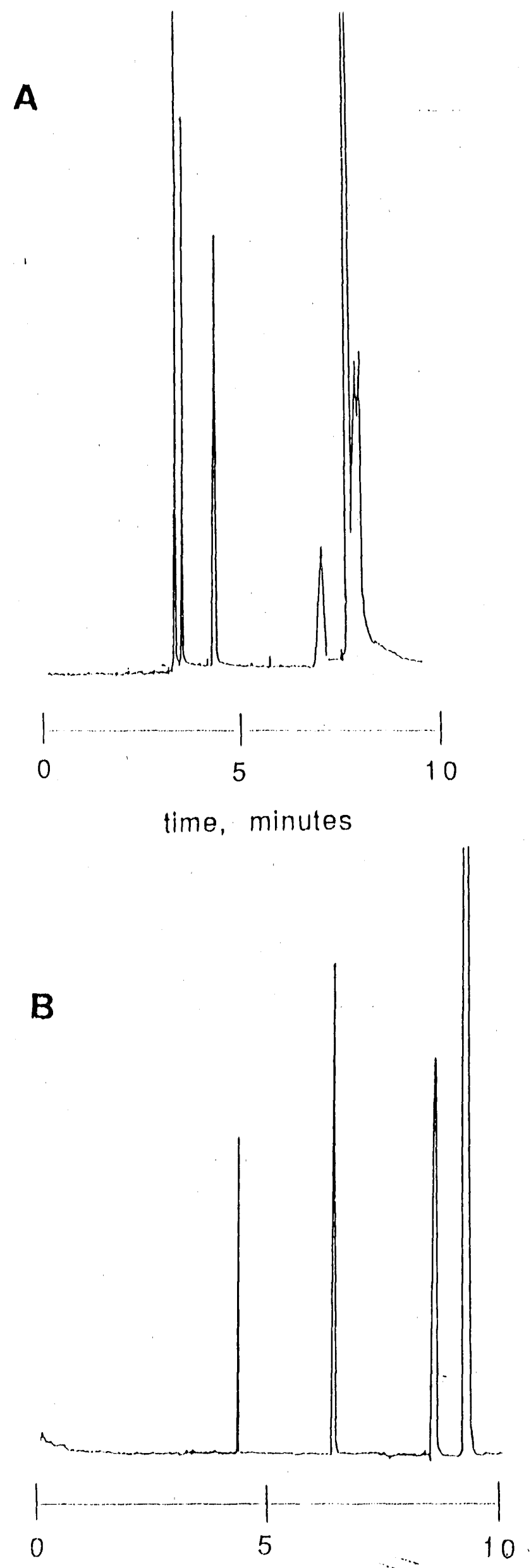

lime, minutes 


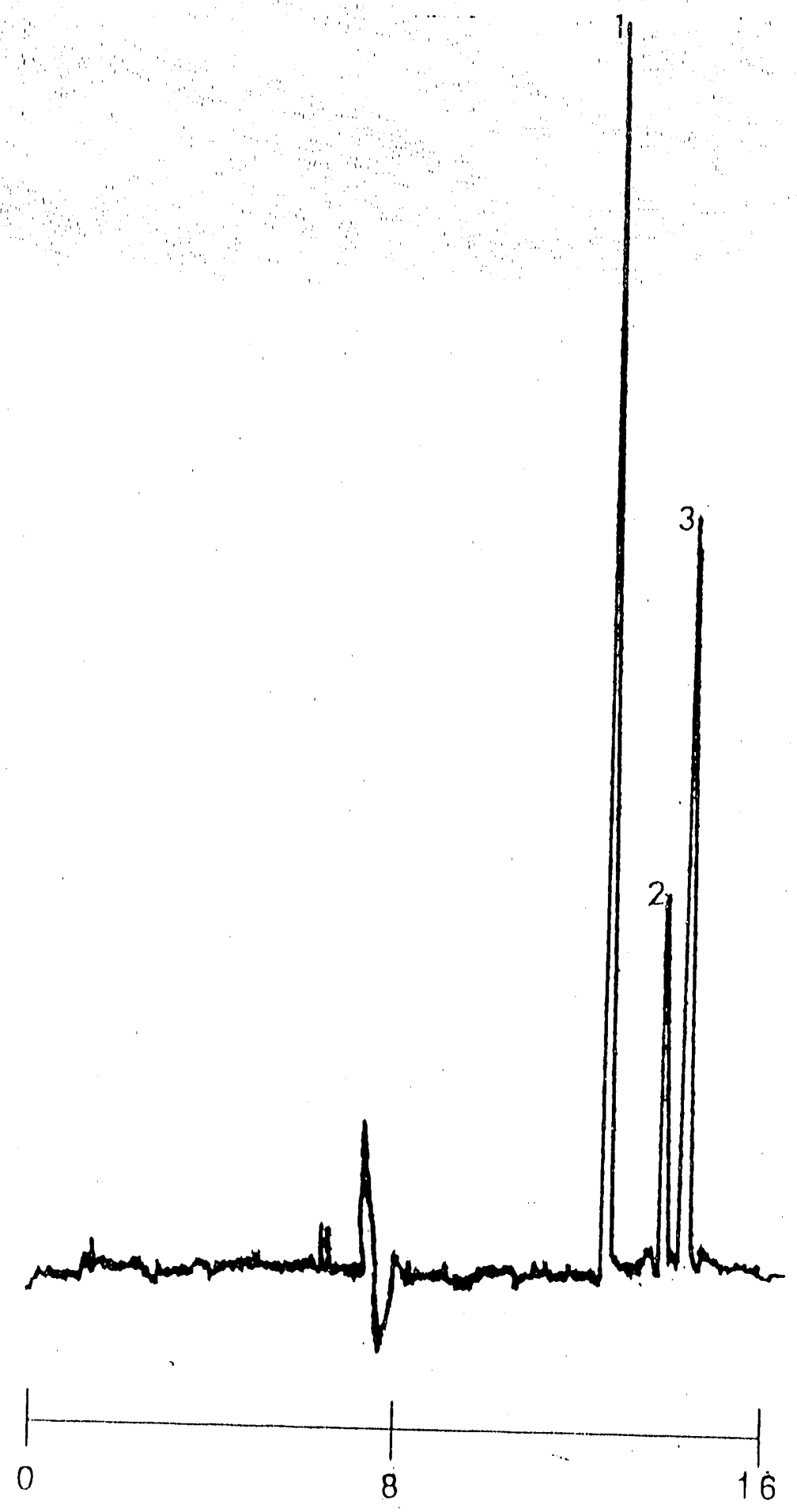

time, mirutes 

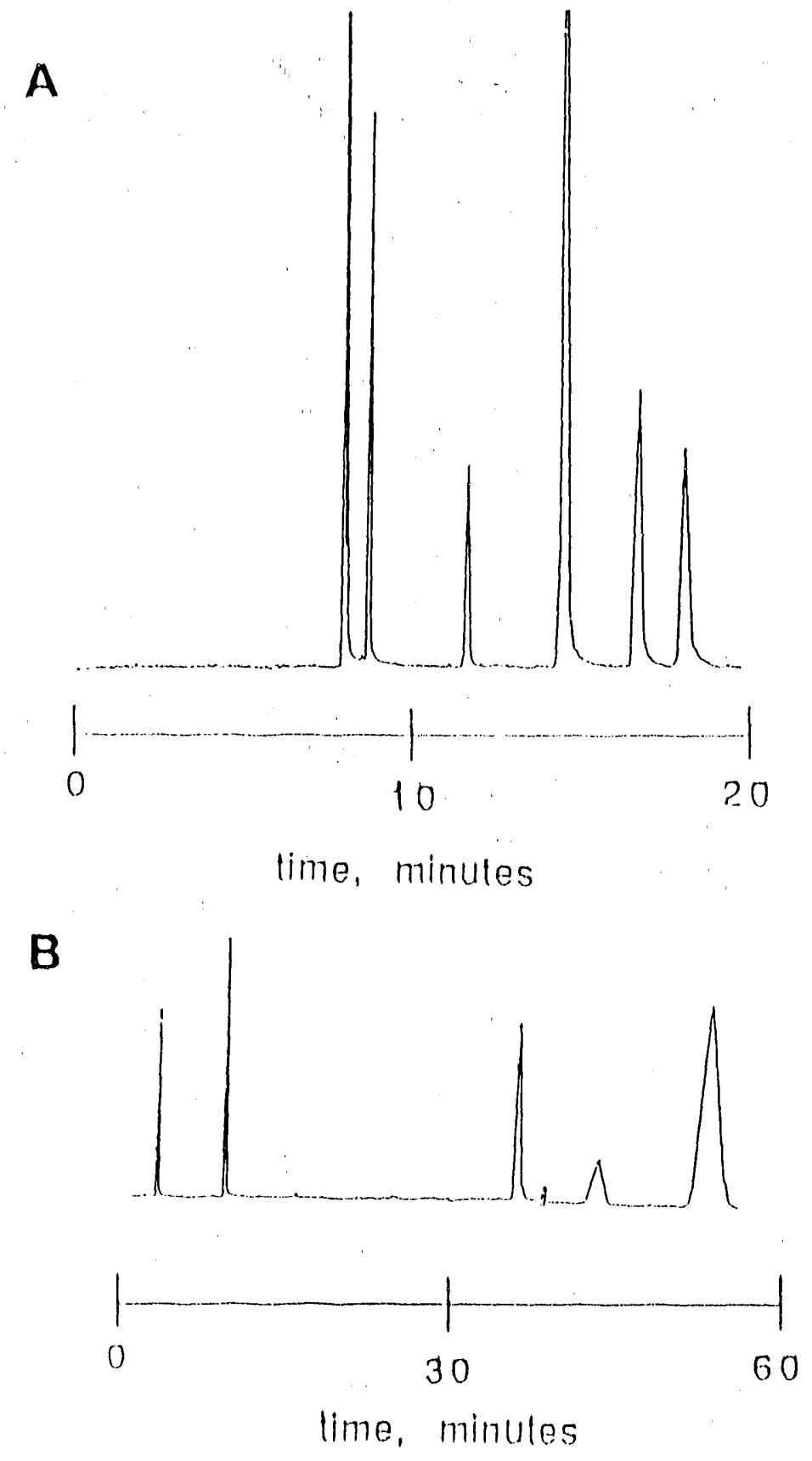


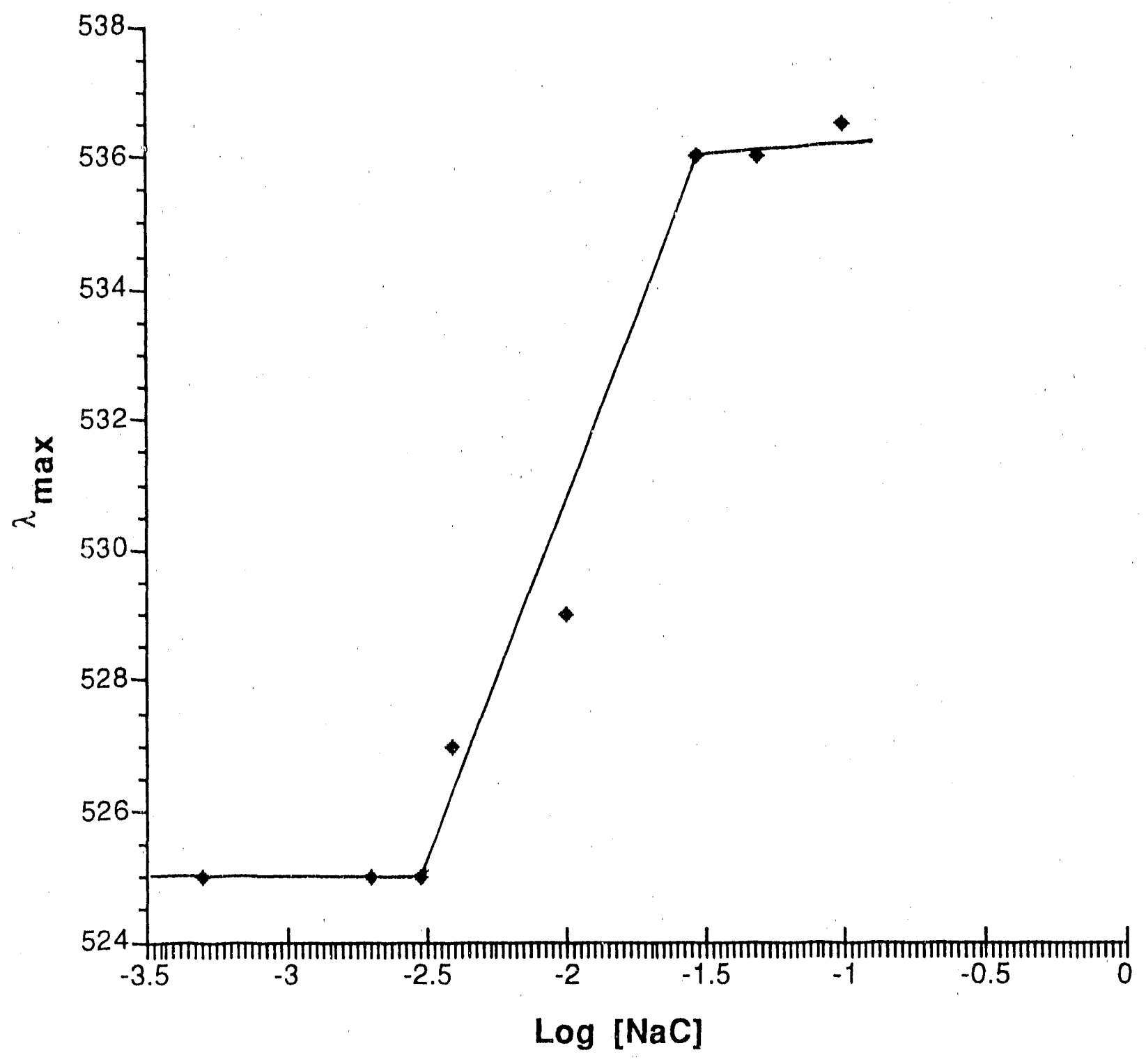




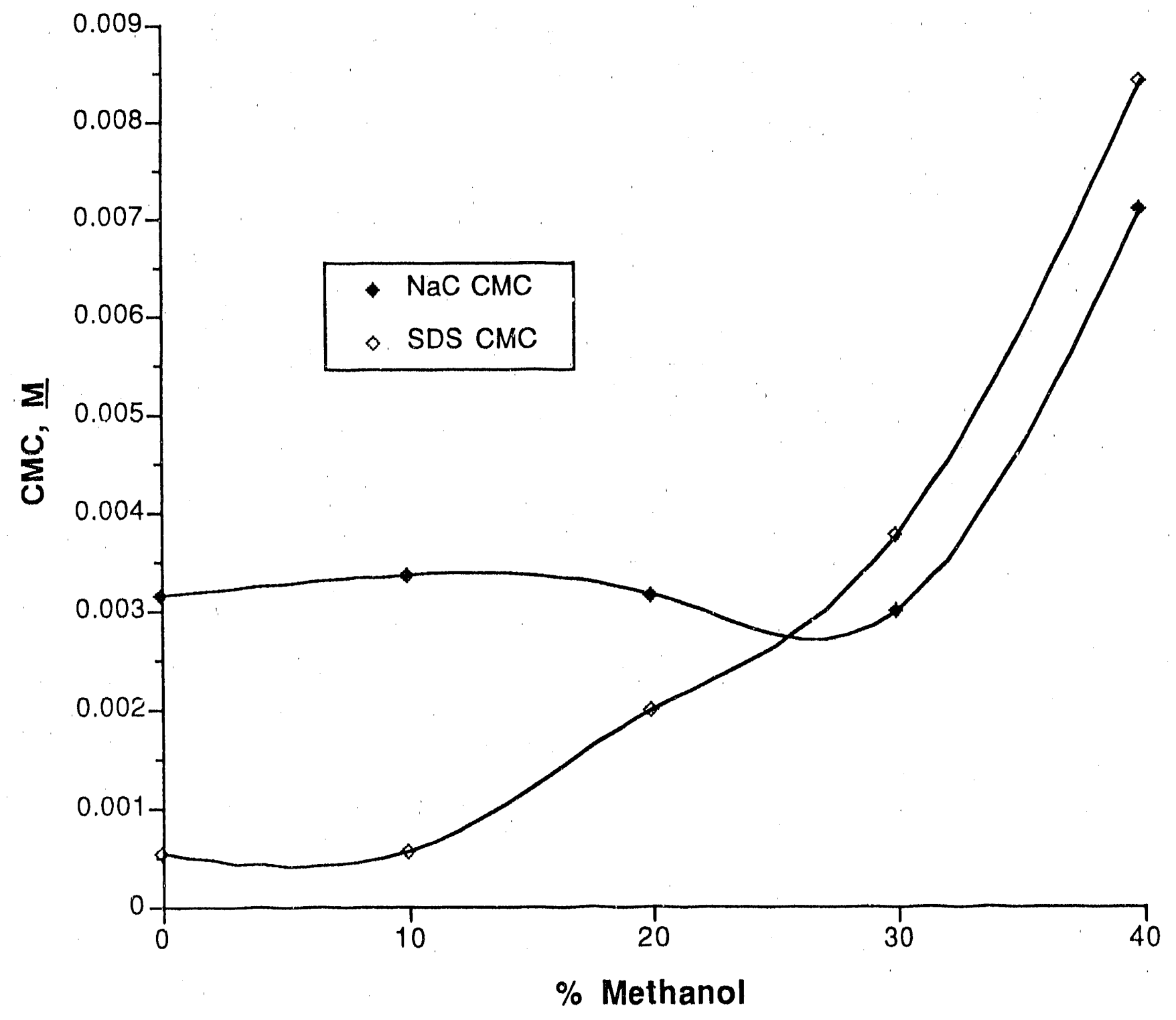


A
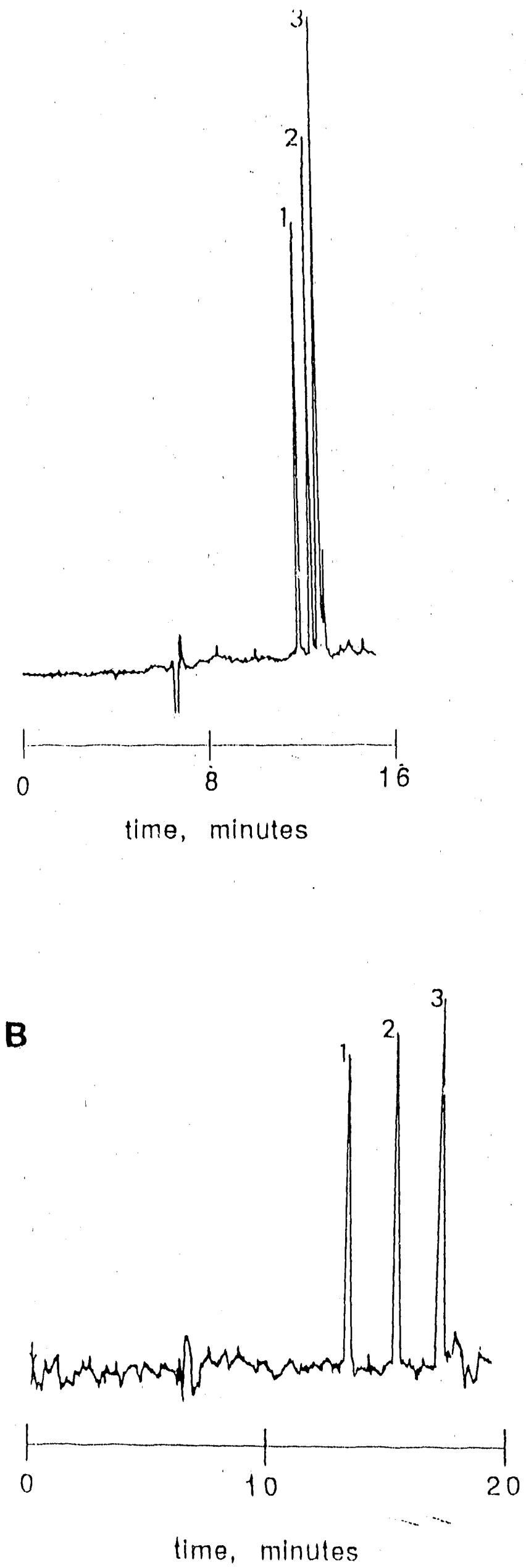


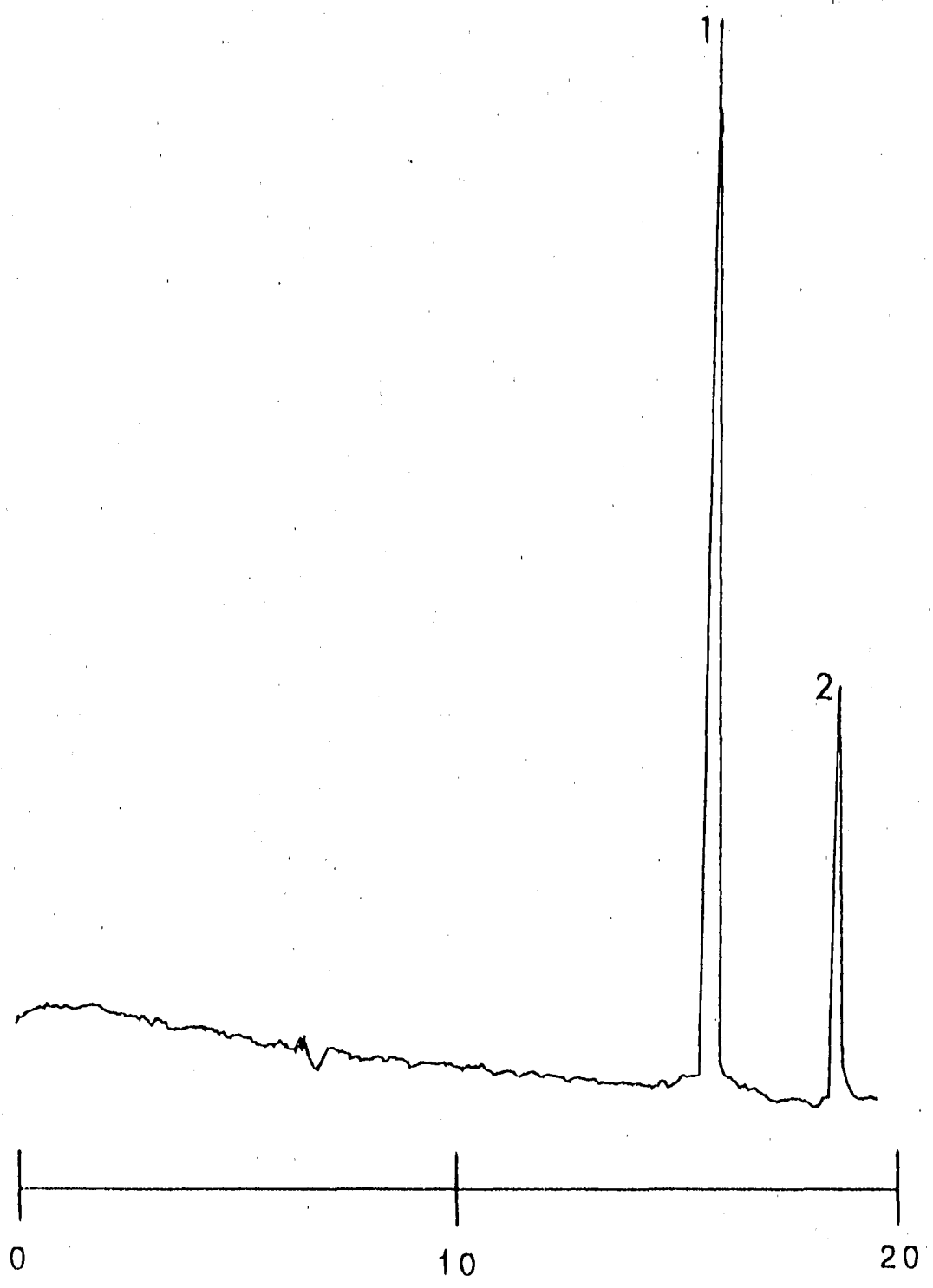

Hime, minutes 

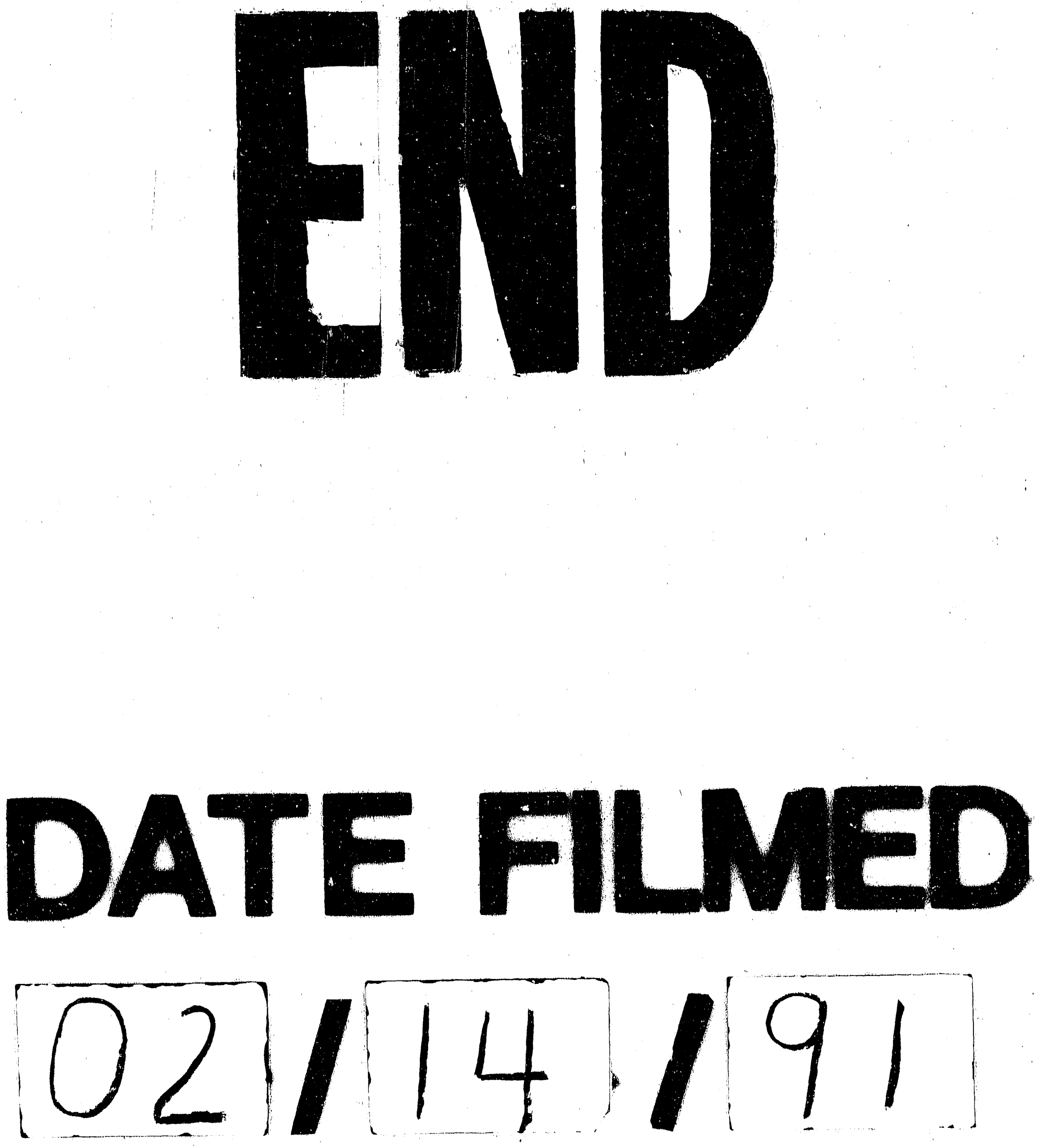